\title{
Collision Tumour of Cerebellopontine Angle in a Patient without Neurofibromatosis Criteria: Case Report
}

Sérgio Neto ${ }^{1 *}$, Cesar Casarolli1, Luiz Henrique Dias Sandon'1, Vinicius Trindade Gomes da Silva1, Francisco Matos Ureña ${ }^{1}$, Nilton Caetano da Rosa ${ }^{2}$, Manoel Jacobsen Teixeira ${ }^{3}$ and Marcos Queirós Gomes ${ }^{1}$

${ }^{1}$ Neurosurgery Division, University of Sao Paulo Medical School, Sao Paulo, Brazil

${ }^{2}$ Division of Surgical Oncology, International Research Center, A.C. Camargo Cancer Center, São Paulo, Brazil

${ }^{3}$ Chairman of Neurosurgery Division, University of Sao Paulo Medical School, Sao Paulo, Brazil

\begin{abstract}
The coexistence of meningioma and schwannoma as two distinct components within the same tumor is extremely rare. They are usually associated with Type 2 Neurofibromatosis (NF-2) but there are some isolated reports of cases without confirmed diagnosis or in association with cancer and/or post irradiation cancer patients. The authors present a case of a collision tumor of the CPA with a presumed diagnosis of NF-2 and a literature review.
\end{abstract}

Keywords: Neurofibromatosis; Collision tumors; Meningioma; Schwannoma

Abbreviations: CPA: Cerebellopontine Angle; NF-2: Type 2 Neurofibromatosis; GTR: Gross Total Resection; CN: Cranial Nerve; MRI: Magnetic Ressonance Imaging

\section{Introduction}

Since the first description by Cushing and Eisenhart in 1938, just over a dozen case reports of mixed schwannomas and meningiomas (both components seen together in the same tumor) arising in patients with NF2 were reported [1]. The simultaneous occurrence of primary brain tumours of different histology in the same anatomical site its a rarely observed situation, more rarer particularly on the CPA $[2,3]$. Such tumours of different origin might be considered as collision, concomitant or contiguous tumours and have been mainly reported in patients with NF2, less often in cases without clinical signs of NF2 [4]. The CPA it's the most reported site of these lesions, but there are a fewer reports of collision tumors of the spine [4,5].

There are some genesis theories that these tumors occur due to a total or partial loss of chromosome 22 and an overexpression of epidermal growth factor that induces schwannomas stimulate the growth of meningiomas in a paracrine fashion $[6,7]$.

The radiographic differentiation of schwannomas and meningiomas of the CPA have been well described: Meningiomas tend to be broadbased, eccentric to the internal auditory canal, and often have adjacent dural enhancement (dural tails). Vestibular schwannomas usually involve and are centered on the internal auditory canal, are more rounded, and rarely have an adjacent dural enhancement. Another distinguishing feature is the hyperostosis seen with $70 \%$ of meningiomas, which rarely occurs with vestibular schwannomas $[8,9]$. The treatment is usually based on the same algorithm used for Schwannomas and meningiomas (GTR and Radiosurgery in specific cases) $[8,10]$.

\section{Case Report}

A 54-year-old male with no past personal or familial medical history, presented a 1-year complaint of unilateral vertigo, headache and a 3-month difficulty for swallowing and face numbness. Patient was referred to Neurosurgery outpatients service after investigation in a private practice and on Physical examination at admission presented: alert and oriented, no gait disorders, a grade IV left hemiparesis and a cranial nerves $(\mathrm{CN})$ syndrome as follows: right V1-V3 hypoesthesia; right VII cranial nerve palsy (House-Brackman 2); right VIII(hypoacusia), IX(decreased right gag reflex), XII(tongue deviation and atrophy).

\section{Investigations}

Haemogram; Urine examination, renal function test, and liver

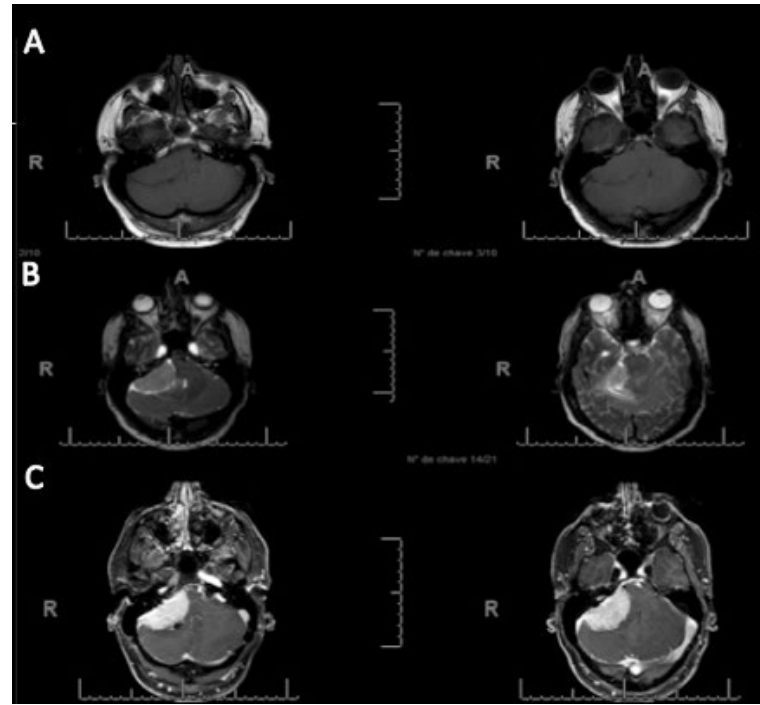

Figure 1: Axial Brain MRI A: T1 weighted image; B: T2 weighted image; C: T1GD weighted image all an extra-axial CPA lesion showing a broad dural base, homogeneous and well circumscribed, with contrast enhancement (C) compressing the brainstem.

*Corresponding author: Sérgio Neto, M.D., Division of Neurosurgery, University of Sao Paulo School of Medicine, Dr. Enéas de Carvalho Aguiar Street, 255-5th Floor, Zipcode: 05403-000-São Paulo, Brazil, Tel: +5511974595327; E-mail: sgsnnc@gmail.com

Received January 12, 2016; Accepted February 10, 2016; Published February 15, 2016

Citation: Neto S, Casarolli C, Sandon LHD, da Silva VTG, Ureña FM, et al. (2016) Collision Tumour of Cerebellopontine Angle in a Patient without Neurofibromatosis Criteria: Case Report. J Pain Manage Med 2: 112

Copyright: (C) 2016 Neto S, et al. This is an open-access article distributed unde the terms of the Creative Commons Attribution License, which permits unrestricted use, distribution, and reproduction in any medium, provided the original author and source are credited. 
Citation: Neto S, Casarolli C, Sandon LHD, da Silva VTG, Ureña FM, et al. (2016) Collision Tumour of Cerebellopontine Angle in a Patient without Neurofibromatosis Criteria: Case Report. J Pain Manage Med 2: 112.

Page 2 of 3

function test were normal. Brain MRI revealed a broad-based lesion on right CPA with brainstem compression and IV ventricle obstruction and secondary Hydrocephalus as shown on Figures 1 and 2.

After case discussion, the authors concluded that the patient had a Meningioma due to the symptoms and image characteristics.

\section{Treatment}

The patient underwent surgery, a retrossigmoid craniotomy was performed and Simpson II resection was achieved, during the surgery an incidental discovery (Figure 3), a small schwannoma of the VIII cranial nerve. Conservative conduct was decided due to the small size of the lesion and the possibility for radiosurgery eventually on followup. Patient presented on the immediate postoperative worsening of VII nerve palsy (HB 2 to HB 4) and slight improvement of the symptoms of $\mathrm{V}$ nerve deficit. A postoperative brain CT showed an adequate resection of the lesion (Figure 4)

The specimen was sent for routine histopathological examination.

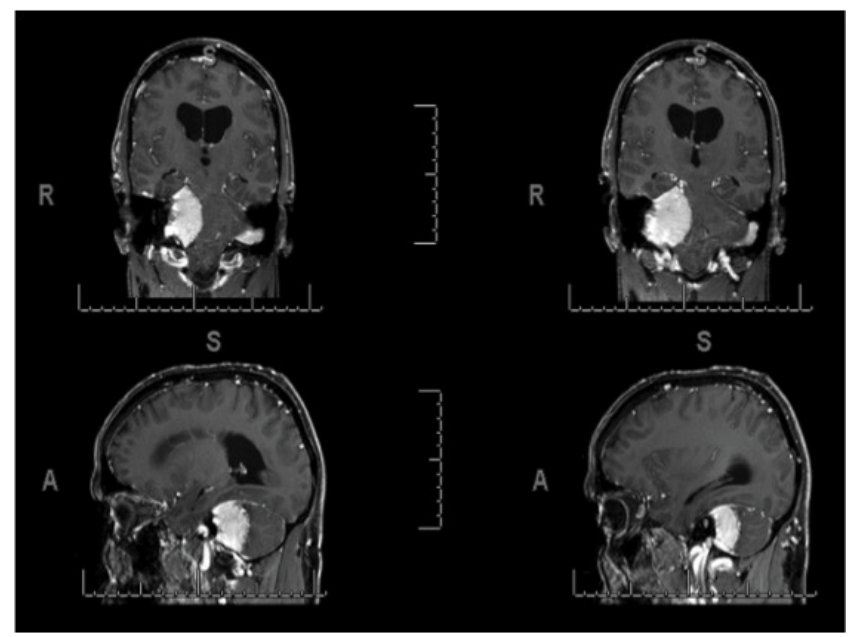

Figure 2: Coronal and Sagittal Brain MRI T1 GD weighted image CPA lesion showing a broad dural base, homogeneous and well circumscribed, with contrast enhancement $(\mathrm{C})$ compressing the brainstem.

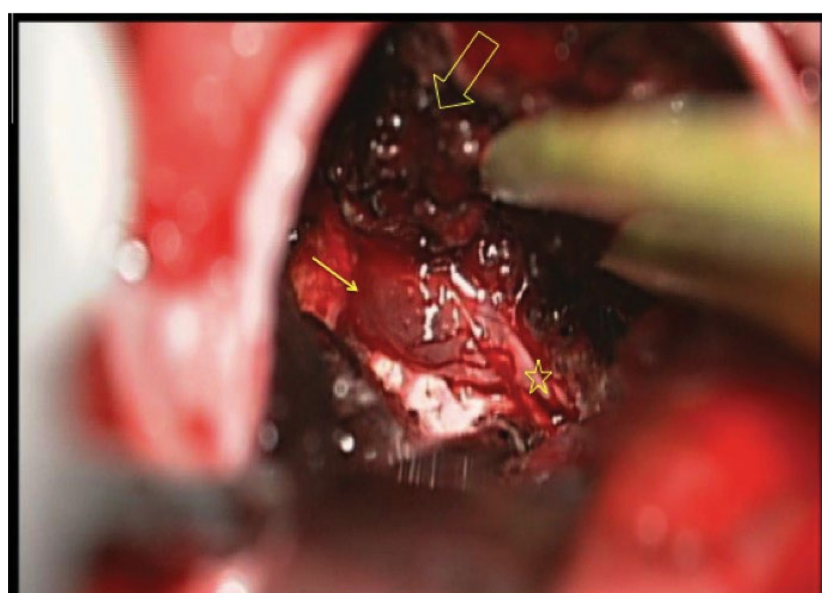

Figure 3: Intraoperative imaging: incidental finding of a VIII cranial nerve Schwannoma (small arrow) and involved VIII cranial nerve (star); partial ressected CPA meningioma (big arrow).
Multiple paraffin sections were studied using haematoxylin and eosin. The sections showed a tumor composed by two histological components (Meningioma and Schwannoma).

\section{Outcome and follow-up}

On the first month outpatient visit, patient presented improvement of the previous reported immediate facial palsy (from $\mathrm{HB} 4$ to $\mathrm{HB} 2$ ) and maintained the VIII cranial nerve deficit and awaits for a new audiometry for comparison.

\section{Discussion}

When two tumors of discrete pathology occurring simultaneously and in close proximity to each other have been termed 'collision tumors' [10]. Meningioma and vestibular schwannoma (VS) are the most and second most common intracranial benign tumors. In the cerebellopontine angle (CPA), these tumors comprise $6-15 \%$ and $80 \%$, respectively, of all tumors [11].

Multiple primary brain tumors are common in patients with phakomatoses, such as NF-2. This disease also known as "multiple inherited schwannomas, meningiomas, and ependymomas syndrome" (MISME syndrome) is an extremely rare (Table 1), inherited autosomal dominant disease characterized by the development of bilateral schwannomas in the region of the vestibular or eighth cranial nerve (in $90 \%$ of cases) $[4,11]$.

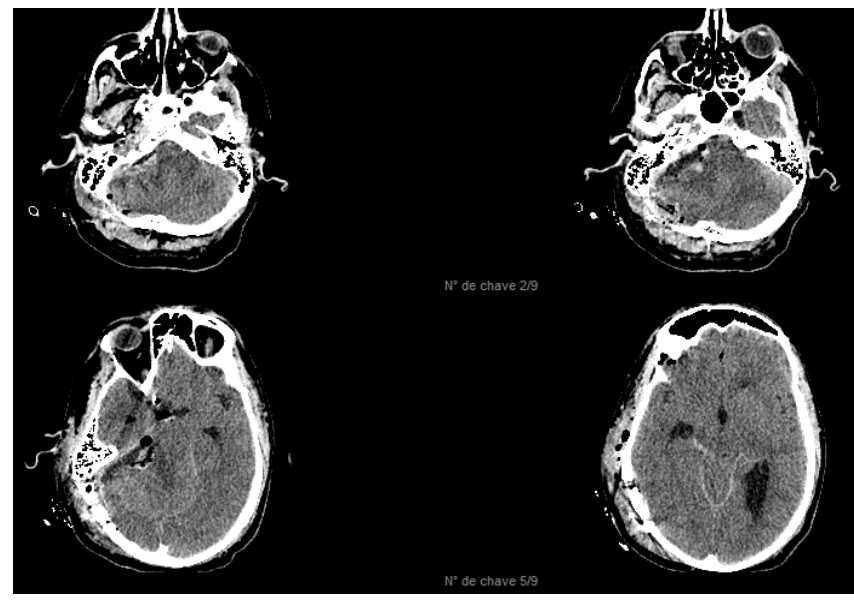

Figure 4: Brain $\mathrm{CT}$ : immediate post operative scan revealing adequate resection.

\begin{tabular}{|c|c|c|c|c|}
\hline Author & Year & $\begin{array}{c}\text { Tumor } \\
\text { side }\end{array}$ & Age/sex & $\begin{array}{c}\text { Radiological } \\
\text { differentiation of two } \\
\text { distinct tumors on } \\
\text { preoperative. Imaging }\end{array}$ \\
\hline $\begin{array}{c}\text { Gardner and } \\
\text { Turner [12] }\end{array}$ & 1939 & Left & $48 / F$ & $\begin{array}{c}\text { Not possible (only } \\
\text { Roentgenograms available) }\end{array}$ \\
\hline $\begin{array}{c}\text { Thomassin et } \\
\text { al. [13] }\end{array}$ & 1991 & Right & $64 / F$ & Not possible \\
\hline $\begin{array}{c}\text { Wilms et al. [14] } \\
\text { Chandra and } \\
\text { Hedge [15] }\end{array}$ & 1992 & Right & $47 / F$ & Possible \\
\hline $\begin{array}{c}\text { Izci et al. [16] } \\
\text { Grauvogel J et } \\
\text { al. [11] }\end{array}$ & 2000 & Right & $35 / F$ & Possible \\
\hline Present case & 2010 & Left & $46 \mathrm{~F}$ & Possible \\
\hline
\end{tabular}

Table 1: Summary of previously reported cases of Collision tumors of CPA. 
Citation: Neto S, Casarolli C, Sandon LHD, da Silva VTG, Ureña FM, et al. (2016) Collision Tumour of Cerebellopontine Angle in a Patient without Neurofibromatosis Criteria: Case Report. J Pain Manage Med 2: 112.

In spite of the overlapping morphological features, cases have been reported, such as the present one, in which the two components of the mixed acoustic tumor show different antigenic profiles, with S-100 protein immunoreactivity being positive in schwannomatosis areas and negative in meningotheliomatous foci [7-16].

\section{Conclusion}

In conclusion, meningioma and Vestibular Schwannomas (VS) may very rarely occur coincidentally in the same

CPA. These tumors can usually be safely and completely removed with a single surgical suboccipital approach [11].

\section{Disclosures}

The authors declared no potential conflicts of interest.

\section{References}

1. Gelal F, Rezanko T, Uyaroglu MA, Tunakan M, Bezircioglu H (2005) Islets of meningioma in an acoustic schwannoma in a patient with neurofibromatosis-2: pathology and magnetic resonance imaging findings. Acta Radiol 46: 519-522.

2. Chahlavi A, Staugaitis SM, Yahya R, Vogelbaum MA (2005) Intracranial collision tumor mimicking an octreotide SPECT positive and FDG-PET negative meningioma. J Clin Neurosci 12: 720-723.

3. Matyja E, Kunert P, Grajkowska W, Marchel A (2012) Coexistence of meningioma and schwannoma in the same cerebellopontine angle in a patients with NF2. Folia Neuropathol 50: 166-172.

4. Rasheed F, Fatima S, Ahmad Z (2015) Triad of Intraspinal Meningioma, Schwannoma, and Ependymoma: Report of an Extremely Rare Case. Int $J$ Surg Pathol 24: 55-58.

5. Kimmel RA, Doherty J, Slattery WH 3rd, Linthicum FH Jr (2013) Recurrent Schwannoma Postirradiation: Histological Review Reveals Mixed Schwannoma and Meningioma. Otolaryngol Head Neck Surg 148: 886-888.
6. Chen AF, Samy RN, Gantz BJ (2001) Cerebellopontine angle tumor composed of Schwann and meningeal proliferations. Arch Otolaryngol Head Neck Surg 127: $1385-1389$

7. Pallini R, Tancredi A, Casalbore P, Mercanti D, Larocca LM, et al. (1998) Neurofibromatosis type 2: growth stimulation of mixed acoustic schwannoma by concurrent adjacent meningioma: possible role of growth factors. Case report. J Neurosurg 89: 149-154.

8. Kutz JW, Barnett SL, Hatanpaa KJ, Mendelsohn DB (2009) Concurrent vestibular schwannoma and meningioma mimicking a single cerebellopontine angle tumor. Skull Base 19: 443-446.

9. Leeman DJ, Chandrasekhar SS, Brackmann DE, Poletti BJ (1997) Collision tumors at the cerebellopontine angle: case report with literature review. Otolaryngol Head Neck Surg 117: S76-80.

10. Muzumdar DP, GoelA(2004)Acoustic schwannoma and petroclival meningioma occurring as collision tumours: a case report. J Clin Neurosci 1: 207-210.

11. Grauvogel J, Grauvogel TD, Taschner C, Baumgartner S, Maier W, et al. (2010) A Rare Case of Radiologically Not Distinguishable Coexistent Meningioma and Vestibular Schwannoma in the Cerebellopontine Angle - Case Report and Literature Review. Case Rep Neurol 2: 111-117.

12. Gardner WJ, Turner OA (1939) Multiple intracranial tumors. JAMA 113: 111-113.

13. Thomassin JM, Pellet W, Abram D, Korchia D (1991) [Tumors of the cerebellopontine angle. Fortuitous association of meningioma and neurinoma]. Ann Otolaryngol Chir Cervicofac 108: 248-252.

14. Wilms G, Plets C, Goossens L, Goffin J, Vanwambeke K (1992) The radiological differentiation of acoustic neurinoma and meningioma occurring together in the cerebellopontine angle. Neurosurgery 30: 443-446.

15. Chandra PS, Hegde T (2000) A case of coexisting cerebellopontine angle meningioma and schwannoma. Neurol India 48: 198.

16. Izci Y, Secer HI, Gonul E, Onguru O (2007) Simultaneously occurring vestibular schwannoma and meningioma in the cerebellopontine angle: case report and literature review. Clin Neuropathol 26: 219-223. 